\title{
Immunoglobulin production is impaired in protein-deprived mice and can be restored by dietary protein supplementation
}

\section{J.F. Amaral' ${ }^{1}$, D.A. Foschetti ${ }^{1}$, F.A. Assis ${ }^{1}$, J.S. Menezes², N.M. Vaz ${ }^{1}$ and A.M.C. Faria ${ }^{1}$}

\author{
${ }^{1}$ Departamento de Bioquímica e Imunologia, Instituto de Ciências Biológicas, \\ Universidade Federal de Minas Gerais, Belo Horizonte, MG, Brasil \\ ${ }^{2}$ Departamento de Imunologia, Instituto de Ciências Biomédicas, \\ Universidade de São Paulo, São Paulo, SP, Brasil
}

\begin{abstract}
Correspondence
A.M.C. Faria

Departamento de Bioquímica e

Imunologia

ICB, UFMG

Av. Antônio Carlos, 6627

31270-901 Belo Horizonte, MC

Brasil

Fax: +55-31-3499-2640

E-mail: afaria@icb.ufmg.br

Research supported by FAPEMIG and CNPq. J.F. Amaral and D.A. Foschetti are recipients of scholarships from CAPES and FAPEMIG, respectively. N.M. Vaz and A.M.C. Faria are the recipients of fellowships from $\mathrm{CNPq}$
\end{abstract}

Publication supported by FAPESP.

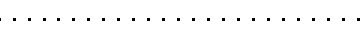

Received January 30, 2006 Accepted August 3, 2006

\begin{abstract}
Most contacts with food protein and microbiota antigens occur at the level of the gut mucosa. In animal models where this natural stimulation is absent, such as germ-free and antigen-free mice, the gutassociated lymphoid tissue (GALT) and systemic immunological activities are underdeveloped. We have shown that food proteins play a critical role in the full development of the immune system. C57BL/ 6 mice weaned to a diet in which intact proteins are replaced by equivalent amounts of amino acids (Aa diet) have a poorly developed GALT as well as low levels of serum immunoglobulins (total Ig, IgG, and $\operatorname{IgA}$, but not IgM). In the present study, we evaluated whether the introduction of a protein-containing diet in 10 adult Aa-fed C57BL/6 mice could restore their immunoglobulin levels and whether this recovery was dependent on the amount of dietary protein. After the introduction of a casein-containing diet, Aa-fed mice presented a fast recovery (after 7 days) of secretory $\operatorname{IgA}$ (from 0.33 to $0.75 \mathrm{mg} / \mathrm{mL}$, while in casein-fed mice this value was $0.81 \mathrm{mg} / \mathrm{mL}$ ) and serum immunoglobulin levels (from 5.39 to $10.25 \mathrm{mg} / \mathrm{mL}$ of total Ig). Five percent dietary casein was enough to promote the restoration of secretory $\operatorname{Ig} \mathrm{A}$ and serum immunoglobulin levels to a normal range after 30 days feeding casein diet (as in casein-fed mice - 15\% by weight of diet). These data suggest that the defect detected in the immunoglobulin levels was a reversible result of the absence of food proteins as an antigenic stimulus. They also indicate that the deleterious consequences of malnutrition at an early age for some immune functions may be restored by therapeutic intervention later in life.
\end{abstract}

Most contacts with foreign antigens occur in the gut mucosa, with these antigens being represented by food proteins and the autochthonous microbiota (1). The presence of a large gut-associated lymphoid tissue (GALT) has been generally attributed to stim-
Key words

- Food proteins

- Immunoglobulins

- Maturation

- Mucosa ulation by antigens from the microbiota, because this tissue is drastically reduced in germ-free animals. Germ-free mice bear smaller Peyer's patches, sparse lamina propria cells and half of the normal number of intraepithelial lymphocytes (2). Levels of 
secretory $\operatorname{Ig} \mathrm{A}$, as well as of serum $\operatorname{Ig} \mathrm{A}$ and $\mathrm{IgG}$, but not $\mathrm{IgM}$, are also reduced in these animals (3). Immunological alterations observed in antigen-free mice, which are deprived of both microbial and dietary stimulation, are more severe (4-7), suggesting that dietary proteins also participate in the immunological development.

We have previously shown that food proteins alone play a key role in the full maturation of the immune system. C57BL/6 mice weaned to a diet in which intact proteins are replaced by equivalent amounts of amino acids (Aa diet) present an immature immune system as measured by several parameters. Adult (8-12 weeks old) Aa-fed mice show a poorly developed GALT with lower numbers of intraepithelial lymphocytes and lamina propria cells and impaired production of secretory IgA compared to control mice. They also present a reduction in the size of Peyer's patches and their germinal centers compared to mice fed a control casein-containing diet. In addition, levels of serum IgG and IgA but not IgM are reduced in Aa-fed mice. In vitro cytokine production by $\mathrm{T}$ cells from several lymphoid organs of these mice shows a predominant $\mathrm{Th} 2$ profile with a high concentration of IL-10 and IL-4, and a low concentration of interferon gamma. Thus, in all immunological parameters examined, these adult animals resemble suckling mice (8), suggesting that stimulation by food proteins after weaning plays a critical role in the maturation of the immune system (9). Mice fed an elemental diet since weaning present similar defects in immune function when they become adults (10).

Two important questions arose from our previous data: a) whether the impairment in immune function associated with dietary protein deprivation was reversible in adult animals, and, if so, b) which was the minimum concentration of dietary protein necessary to promote the recovery of immunological function. In the present study, we addressed these two questions. First, we examined the ef- fects, during a period ranging from 1 to 30 days, of introducing a casein-containing diet (control diet) to adult mice that had been fed a protein-free diet (Aa diet) since weaning. Then, we evaluated the influence of different amounts of dietary proteins on the recovery of immune function in adult Aa-fed mice.

To investigate the immunological impact of the introduction of dietary proteins to Aafed adult mice, we first reared C57BL/6 mice on an Aa diet from weaning (3 weeks of age) to adulthood ( 8 weeks of age). The inbred female C57BL/6 mice used in the present study were bred and reared under standard conditions in our animal facility. All experimental protocols were approved by the Ethics Committee for Animal Research of UFMG. The control diet contained $15 \%$ casein as protein source and was named Cas diet. The experimental diets (Rhoster Indústria e Comércio Ltda., São Paulo, SP, Brazil) were isocaloric and identical with respect to all other nutrients, according to the 1993 AIN-93G (American Institute of Nutrition) guidelines (11). Diet (in solid form as pellets) and tap water were given ad libitum to all groups and mice were maintained under standard open cage conditions throughout the experiments.

Since Aa-fed mice have a typical decrease in serum IgG and IgA levels as well as in secretory IgA levels (9), these parameters were chosen to evaluate the immunological development of mice under different diet regimens. Mice were bled under anesthesia from the axiliary plexus and sera were obtained after clotting and centrifugation. Secretory $\operatorname{IgA}$ was measured in the intestinal lavage fluid collected after isolation of the small intestine of individual mice. Antibody levels were measured by standard capture ELISA. Plates were coated with goat antimouse Ig (Southern Biotechnology Association, Inc., Birmingham, AL, USA) and serum immunoglobulin isotypes were detected using peroxidase-labeled rat antimouse $\operatorname{Ig}, \operatorname{IgG}$, IgM, or IgA (Sigma, St. 
Louis, MO, USA). Reaction was read at 450 $\mathrm{nm}$ using an ELISA reader (Bio-Rad, Hercules, CA, USA). The concentration of immunoglobulin was determined using a standard curve obtained with purified Igs of each isotype (Southern Biotechnology Association, Inc.). Data are reported as means \pm SEM and significant differences between groups were determined by the Student $t$ test.

Immunoglobulin levels were evaluated 4 weeks after the introduction of a control casein-containing diet (Cas diet) to 8-weekold Aa-fed mice. Local immune function, determined by the levels of secretory $\operatorname{IgA}$ as shown in Figure 1, was reduced in Aa-fed mice compared with Cas-fed mice. However, introduction of a casein-containing diet led to a progressive recovery of secretory $\operatorname{Ig} \mathrm{A}$ concentration in the intestinal mucus (Figure 1A) that reached normal values after $72 \mathrm{~h}$. To investigate whether introduction of dietary proteins had a role in systemic immune function we compared the serum immunoglobulin levels (total Ig, $\operatorname{IgG}$, IgM, and $\operatorname{Ig} \mathrm{A}$ ) of mice exclusively fed the Aa diet to those of Aa-fed mice that received the Cas diet for 4 weeks. As shown in Figure 1B-E, Aa-fed mice had reduced levels of serum immunoglobulins when compared with Casfed mice. When Aa-fed mice were introduced to a casein-containing diet, they presented a gradual recovery in their levels of serum immunoglobulin. Normal serum concentrations of immunoglobulins of all isotypes (except for total Ig) were reached after $72 \mathrm{~h}$ of control diet consumption.

To determine the concentration of dietary protein that was necessary to promote this recovery of immunoglobulin levels we compared the concentration of serum IgA and other serum immunoglobulins in 12week-old mice exclusively fed the Aa-diet (Aa mice) with the concentration of immunoglobulins in 12-week-old Aa-fed mice that were introduced to diets containing increasing amounts of casein $(0.5,2,5,10$, and
$15 \%)$ at 8 weeks of age. To reach a $15 \%$ protein source in each diet, we added complementary amounts of the Aa mixture so that all test diets would contain a known combination of casein amino acids and intact casein. As shown in Figure 2A, Aa-fed mice had a reduced concentration of serum $\operatorname{IgA}$ when compared with control $15 \%$ Cas-fed mice. When $5 \%$ casein was introduced in their diets, Aa-fed mice presented a recovery of their levels of secretory IgA. However, to restore normal serum levels of total Ig and of IgA, a diet containing at least 10\% casein was necessary (Figure 2B and D). Serum IgG and IgM returned to normal levels in mice that were fed a diet containing $5 \%$ casein (Figure 2C and E). Curiously, in these experiments, IgM levels were also reduced in Aa-fed mice although we did not observe reduction in serum IgM in our previous study (9).

In the present study, we demonstrated that the introduction of a casein-containing diet to Aa-fed C57BL/6 mice when they were adults completely reversed the immunological effects of protein deprivation, suggesting that these effects were indeed a reversible result of low stimulation by food antigens. In 3 days, dietary supplementation of adult mice with $15 \%$ casein was able to restore the levels of all immunoglobulin isotypes (locally and systemically) to normal values. The recovery was dependent on the concentration of protein in the diet. Local secretory $\operatorname{Ig} \mathrm{A}$ as well as serum $\operatorname{IgG}$ and $\operatorname{IgM}$ were more susceptible to recovery and 5\% casein was sufficient to fully restore their concentration. On the other hand, at least $10 \%$ casein was necessary to restore normal levels of serum IgA, suggesting that there is a hierarchy of dependency on stimulation by food proteins. Recovery of serum immunoglobulin levels and secretory IgA was also observed in germ-free mice that were either monoassociated with bacteria or transferred to conventional conditions (12). Our hypothesis is that food proteins and bacterial 


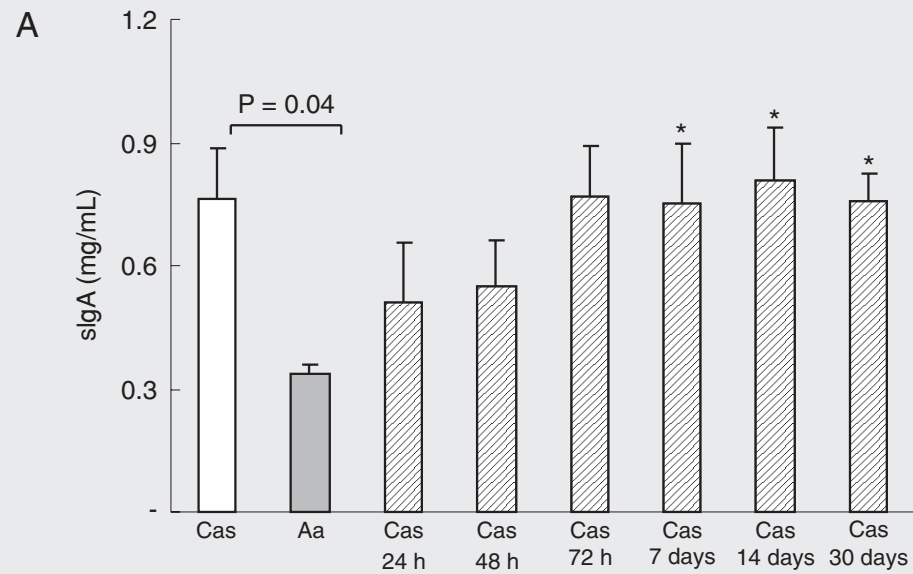

B
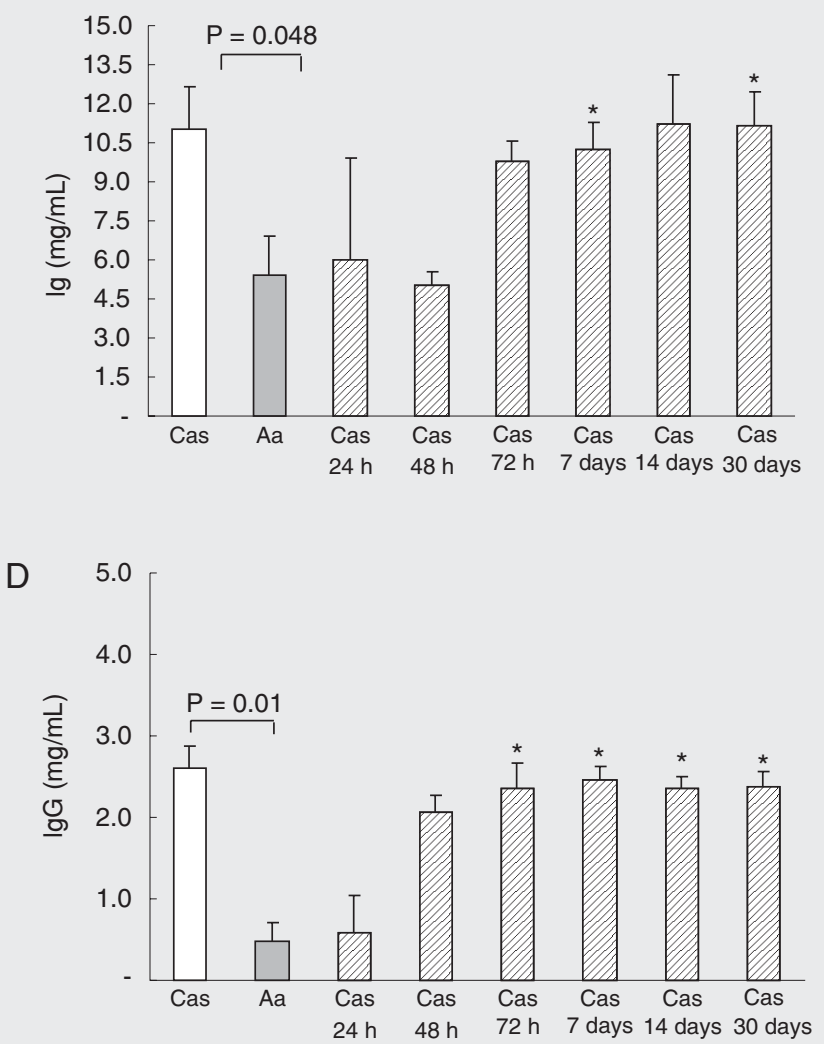

C
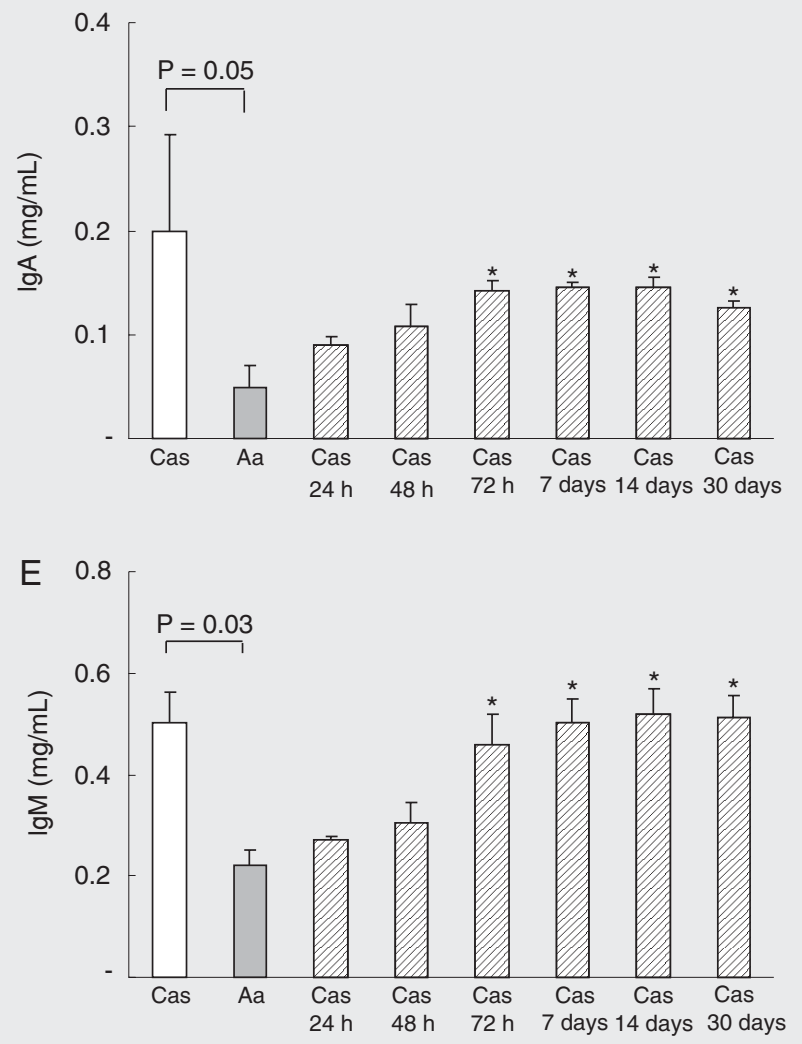

Figure 1. Introduction of dietary protein leads to a recovery of immunoglobulin production in adult amino acid (Aa)-fed mice. Casein (Cas)-fed mice (white bars), Aa-fed mice (grey bars) and initially Aa-fed mice that were later introduced to a diet containing $15 \%$ casein (hatched bars) were sacrificed at 12 weeks of age. The Cas diet was introduced to Aa-fed mice 4 weeks before sacrifice. The intestine was isolated and intestinal lavage fluid was collected for secretory $\lg A(\mathrm{slg} A)$ measurement. Animals were bled from the auxiliary plexus and sera were separated by centrifugation. slgA (A), and serum immunoglobulins, total $\lg (B), \lg A(C), \lg G(D)$, and $\lg M(E)$ were measured by capture ELISA. Data are reported as the mean $\pm S D$ for $4-5$ mice per group and are representative of results of two separate experiments. ${ }^{*} \mathrm{P}<0.05$ compared to Aa-fed mice (Student $t$-test). 


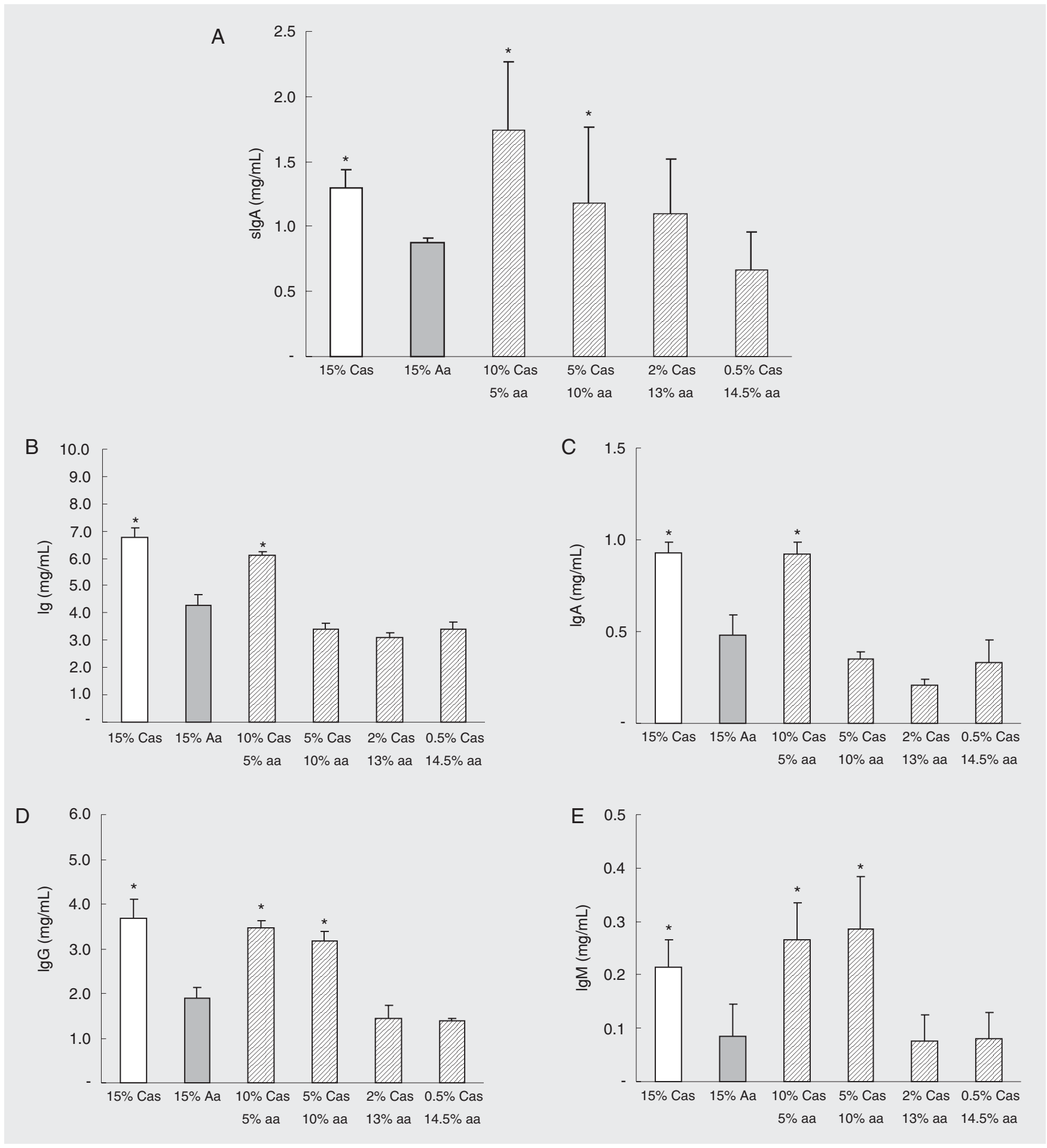

Figure 2. Recovery of immunoglobulin production was dependent on the concentration of dietary protein. White bars correspond to animals that were fed a 15\%-casein (Cas) diet. Grey bars indicate animals fed a 15\% amino acid (Aa) diet. Hatched bars indicate mice that received test diets containing variable combinations of casein and amino acids to reach $15 \%$ total protein. Intestinal lavage fluid and serum were collected for immunoglobulin evaluation. Secretory $\lg A(\operatorname{sg} A, A)$, and serum immunoglobulins, total $\lg (B), \lg A(C), \lg G(D)$, and $\lg M(E)$ were measured by capture ELISA. Data are reported as the mean $\pm S D$ for $4-5$ mice per group and are representative of results of two separate experiments. ${ }^{*}<0.05$ compared to all other groups (Student $t$-test). 
antigens that contact and penetrate the gut mucosa drive lymphocytes to proliferate and differentiate into activated productive cells in lymphoid organs, especially in the GALT. In agreement with this hypothesis, the frequency of activated $\mathrm{T}$ and $\mathrm{B}$ cells is reduced in Peyer's patches as well as in mesenteric and peripheral lymph nodes of Aa-fed mice (9). Starting at birth and drastically increasing after weaning, contact with gut-derived natural antigens seems to stimulate the development of a physiological tonus for the immune system. Since the weaning period coincides with hormonal, nutritional and immunological changes, one question raised by our previous study was whether this period would represent a unique window in immunological development. In the present study, we observed that the decrease in immunoglobulin levels does not constitute a permanent deficiency and can be readily corrected at a later period by adding back the antigens that were missing. Interestingly, introduction of the Aa diet for a similar period of time (4-8 weeks) to fully mature adult mice had no effect on immunoglobulin levels or on number of lymphoid cells in the GALT and other lymphoid organs (data not shown). This indicates that when immunological maturation is already accomplished, these natural antigens are no longer crucial. This may contribute to explain why chronic malnutrition in adults leads to less severe immunological effects than in children (13). Taken together, our data suggest that the critical role of stimulation by food proteins in normal immunoglobulin production is independent of any special time point when immune maturation must start.

Our data have clinical implications since they indicate that malnutrition at an early age (during the weaning period) may have deleterious consequences for the development of the immune system. At the same time, they also indicate the possibility of therapeutic intervention later in life to restore immune function. The defect in immunoglobulin production, for instance, seems to be fully reversed within a short period of time by low amounts of protein in the diet.

\section{Acknowledgments}

We would like to acknowledge Ilda Marçal de Souza for excellent care of our animal facility.

\section{References}

1. Brandtzaeg P. Development and basic mechanisms of human gut immunity. Nutr Rev 1998; 56: S5-S18.

2. Bandeira A, Mota-Santos T, Itohara S, Degermann S, Heusser C Tonegawa $S$, et al. Localization of gamma/delta T cells to the intestinal epithelium is independent of normal microbial colonization. $J$ Exp Med 1990; 172: 239-244.

3. Wostmann B. Germ-free and gnotobiotic animal models. In: Melby EC Jr, Altman NH (Editor), Handbook of Laboratory Animal Science. Cleveland: CRC Press; 1996.

4. Hashimoto K, Handa H, Umehara K, Sasaki S. Germfree mice reared on an "antigen-free" diet. Lab Anim Sci 1978; 28: 38-45.

5. Haury M, Sundblad A, Grandien A, Barreau C, Coutinho A, Nobrega $A$. The repertoire of serum IgM in normal mice is largely independent of external antigenic contact. Eur J Immunol 1997; 27: 1557-1563.

6. Hooijkaas H, Benner R, Pleasants JR, Wostmann BS. Isotypes and specificities of immunoglobulins produced by germ-free mice fed chemically defined ultrafiltered "antigen-free" diet. Eur J Immunol 1984; 14: 1127-1130.

7. Pereira P, Forni L, Larsson EL, Cooper M, Heusser C, Coutinho A.
Autonomous activation of B and T cells in antigen-free mice. Eur $J$ Immunol 1986; 16: 685-688.

8. Benveniste J, Lespinats G, Adam C, Salomon JC. Immunoglobulins in intact, immunized, and contaminated axenic mice: study of serum IgA. J Immunol 1971; 107: 1647-1655.

9. Menezes JS, Mucida D, Cara DC, Alvarez-Leite JI, Russo M, Vaz $\mathrm{NM}$, et al. Stimulation by food proteins plays a critical role in the maturation of the immune system. Int Immunol 2003; 15: 447-455.

10. Menezes JS, Andrade MC, Senra B, Rodrigues VS, Vaz NM, Faria AM. Immunological activities are modulated by enteral administration of an elemental diet in mice. Clin Nutr 2006; 25: 643-652.

11. Reeves PG, Nielsen FH, Fahey GC Jr. AIN-93 purified diets for laboratory rodents: final report of the American Institute of Nutrition ad hoc writing committee on the reformulation of the AIN-76A rodent diet. J Nutr 1993; 123: 1939-1951.

12. Cebra JJ. Influences of microbiota on intestinal immune system development. Am J Clin Nutr 1999; 69: 1046S-1051S.

13. Chandra RK. Nutrient regulation of immune functions. Forum Nutr 2003; 56: 147-148. 